The alternative approach to gene delivery, using DNAliposome complexes, avoids most if not all of these immunological problems. This method involves combining the new gene with a cationic liposome. DNA-liposome complexes have been used in mice with genetically engineered cystic fibrosis and resulted in partial correction of the chloride transport defect and no toxic effects. ${ }^{7}$ These encouraging if modest results in mice have been replicated in a clinical trial. ${ }^{9}$ Nasal delivery of DNA-liposome complexes to patients with cystic fibrosis produced low levels of gene expression and partial transient correction of the bioelectric defect with no toxicity.

Are such low levels of gene expression and partial correction of function enough to achieve a meaningful clinical effect? If levels of expression in the corrected cells are similar to those in clinically normal heterozygotes the answer must be yes. In mice lacking $\beta$-glucoronidase (which are models of mucopolysaccharidosis VII) autologous implants of genetically corrected skin fibroblasts led to $0 \cdot 5-6 \%$ of the normal level of circulating $\beta$-glucoronidase. ${ }^{10}$ This was sufficient to abolish the lysosomal storage lesions normally present in the liver and spleen of these mice. In addition we have shown that a very low level of cystic fibrosis transmembrane conductance regulator $\mathrm{mRNA}(\sim 5 \%$ of wild type levels) only partially corrects the chloride conductance defect in mutant mice with cystic fibrosis but restores survival to normal levels. ${ }^{11}$ This demonstrates that the relation between phenotype and gene activity is non-linear, as would be predicted for a recessively inherited disease. ${ }^{12}$ Therefore clinical trials that show minor correction of function may result in major clinical benefit.

In conclusion, research into somatic gene therapy has advanced at an astonishing pace. Preclinical trials in relevant animal models are vital for developing and refining safe, effective strategies. But clinical trials must also be undertaken at an early stage, as patients will present species and disease specific challenges. Data from these trials must then form the basis for further rounds of taboratory based research. The most promising vector systems and cellular targets are still at the stage of conception rather than application. Optimism in gene therapy is well placed, but expectations of immediate clinical success should be tempered.

JULIA DORIN Scientist

MRC Human Genetics Unit,

Western General Hospital,

Edinburgh EH4 2XU

1 Blaese RM, Culver KW, Miller AD, Carter CS, Fleisher T, Clerici M, et al. T lymphocyte- directed gene therapy for ADA-SCID: initial trial results after 4 years. Science 1995;270:475-81.

2 Grossman M, Rader DJ, Muller DWM, Kolansky DM, Kozarsky K, et al . A pilot study of ex vivo gene therapy for homozygous familial hypercholesterolaemia. Nature Medicine 1995;1:1 148-54.

3 Crystal RG. Transfer of genes to hamans: early lessons and obstacles to success. Science 1995;270:404-10.

4 Grubb BR, Pickles RJ, Ye H, Yankaskas JR, Vick RN, Engelhardt JF, et al. Inefficient gene transfer by adenovirus vector to cystic fibrosis airway epithelia of mice and humans. Nature 1994;371:802-6.

5 Knowles MR, Hohneker KW, Zhaoqing Z, Olsen JC, Noah TL, Ping-Chuan, et al. A controlled study of adenoviral-vector-mediated gene transfer in the nasal epithelium of patients with cystic study of adenoviral-vector-mediated gene
fibrosis. N Engl f Med 1995;333:823-31.

6 Yang Y, Trinchieri G, Wilson JM. Recombinant IL-12 prevents formation of blocking IgA antibodies to recombinant adenovirus and allows repeated gene therapy to mouse lung. Nature Medicine 1995;1:890-3.

7 Alton EWFW, Middleton PG, Caplen NJ, Smith SN, Steel DM, Munkonge FM, et al. Noninvasive liposome-mediated gene delivery can correct the ion transport defect in cystic fibrosis mutant mice. Nat Genet 1993;5:135-42.

8 Hyde S, Gill D, Higgins CF, Trezise A, MacVinish L, Cuthbert A, et al. Correction of the ion transport defect in cystic fibrosis transgenic mice by gene therapy. Nature 1993;362:250-5.

9 Caplen NJ, Alton EWFW, Middleton PG, Dorin JR, Stevenson BJ, Gao X, et al. Liposomemediated CFTR gene transfer to the nasal epithelium of patients with cystic fibrosis. Nature mediated CFTR gene
Medicine 1995;1:39-46.

10 Moullier P, Bohl D, Heard J-M, Danos O. Correction of lysosomal storage in the liver and spleen of MPS VII mice by implantation of genetically modified skin fibroblasts. Nat Genet 1993;4 154-9.

11 Dorin JR, Webb S, Farini E, Delaney S, Wainwright B, Smith S, et al. Phenotypic consequence of CFTR modulation in mutant mice: implications for somatic gene therapy. Paediatric Pulmonology 1995;19(suppl 12):231.

12 Kascer H, Burns JA. Molecular basis of dominance. Genetics 1981;97:638-66.

\title{
Health promotion in primary care
}

\section{Even less coherent than before}

In his continuing drive to appease disillusioned and overworked general practitioners, Britain's secretary of state for health has made major concessions over the data on health promotion that general practitioners are required to record. ${ }^{1}$ The more than 120 items of data that were previously required have now been reduced to eight. The move will please those general practitioners who have objected to the "ritualistic collection of risk factors when the public health benefits are marginal," ${ }^{2}$ but the reductions seem to have been driven more by the pressure to reduce paperwork than by a desire for effective disease prevention. In the absence of either a strategic or an evidence based approach to health promotion in primary care, many important items have been lost while others have been inappropriately retained.

Under the new scheme, general practitioners are being asked to record the number of patients in their practice with certain diseases or risk factors: smoking, excess alcohol intake, obesity, coronary heart disease, stroke, transient ischaemic attacks, and a family history of coronary heart disease or stroke. They are also being asked to record the number of patients whose blood pressure has been recorded, but not the number with raised blood pressure.

Some aspects of the new scheme make scientific sense. Obesity is an increasingly serious health problem in England and Wales, and retaining the recording of obesity is sensible. ${ }^{3}$
While moderate alcohol intake may protect against heart disease, excessive intake is harmful and simple advice from a general practitioner has been shown to reduce consumption and improve health. ${ }^{45}$ The requirement to record smoking habits and to establish disease registers for patients with coronary heart disease, stroke, and transient ischaemic attack has also sensibly been retained. Such registers should form the basis of implementing systematic secondary prevention such as aspirin prophylaxis. Equally sensible has been the decision to stop collecting data on diet and physical activity. There are no simple, reliable methods for collecting these data in primary care, so the data already collected on these topics are inconsistent and difficult to interpret.

Other decisions are less easy to explain. More than $10 \%$ of adults in Britain have untreated hypertension, and this proportion increases rapidly with age. ${ }^{3}$ But the new scheme has dropped the previous requirement for general practitioners to record the number of patients with raised blood pressure. Meanwhile, it asks them to continue to record far less useful information on patients' family history of cardiovascular disease. This decision seems to have more to do with the ease of recording the information than any benefit it is likely to produce.

There is little evidence that a family history of cardiovascular disease on its own is useful in identifying those 
patients requiring active management. ${ }^{6}$ If this information helped to identify those with inherited hyperlipidaemias it would be useful. However, the incidence of familial hypercholesterolaemia is about 1 in 500,7 and only half of these people have a family history of coronary heart disease. ${ }^{8}$ From these figures, not more than one case of familial hypercholesterolaemia would be found in 1000 screened adults, with 170 patients requiring a blood test. ${ }^{8}$ One further case of familial hypercholesterolaemia would go undetected, as would $50-65 \%$ of patients with serum cholesterol concentrations greater than $8 \mathrm{mmol} / 1 .^{6}$

\section{Too important to be bargained away}

But perhaps the most worrying aspect of the new proposals is the abolition of the requirement to stratify the data recorded by age and sex. Without stratification, the data will be uninterpretable and of no value in planning effective health promotion. With most general practices now being computerised, it is simple to produce data stratified by age and sex. This requirement to stratify should be reintroduced, at least in computerised practices.

Health promotion is too important to be used by the Department of Health as a bargaining counter to appease general practitioners who are increasingly disillusioned by an onerous scheme unsupported by science. The whole scheme should be comprehensively reviewed. If financial incentives for health promotion are to be retained, they should be linked to evidence based interventions focused on people at higher risk. A series of hurried decisions has failed to provide a policy for health promotion in primary care that could add length and quality to many lives. An opportunity for a broader review leading to an effective strategy integrating the many agencies involved in disease prevention has been missed.

STEPHEN GILLAM Consultant in public health medicine

Directorate of Strategy and Public Health,

Bedfordshire Health Authority,

Luton LU1 2PL

PETER MCCARTNEY General practitioner and research fellow MARGARET THOROGOOD

Senior lecturer

Health Promotion Sciences Unit,

Department of Public Health and Policy,

London School of Hygiene and Tropical Medicine,

London WC1E 7HT 1 NHS Executive. Letter to chief executives of FHSAs. Leeds: Department of Health, 1995.
(FHSL 68 (95).)
2 Stott N. Screening for cardiovascular risk in general practice. Blanket health promotion is a waste of
resources. BMF 1994;308:285-6.
3 Office of Population Censuses and Surveys. Health Survey for England 1993. London: HMSO, 1995.
4 Wallace P, Cutler S, Haines A. Randomised controlled trial of general practice intervention in
patients with excessive alcohol consumption. BMF 1988;297:663-8.
5 Heather N, Campion PD, Ronald GN, Maccabe D. Evaluation of a controlled drinking minimal
intervention for problem drinkers in general practice (the DRAMS scheme). F R Coll Gen Pract
1987;37:358-63.
6 Imperial Cancer Research Fund OXCHECK Study Group. Prevalence of risk factors for heart
disease in OXCHECK trial: implications for screening in primary care. BMf 1991;302:1057-60.
7 Goldstein JL, Brown MS. Familial hypercholesterolaemia. In: Stanbury JB, Wyngaarden JB,
Fredrickson DS, Goldstein JL, Brown MS, eds. The metabolic basis of inherited disease. 5th ed.
New York: McGraw-Hill, 1993:672-712.
8 Scientific Steering Committee on behalf of the Simon Broom Register Group. Risk of fatal coronary
heart disease in familial hypercholesterolaemia. BMF 1991;303:893-6.

\section{Treatment resistance in schizophrenia}

\section{Alternative drugs may offer clearer understanding of underlying mechanisms}

Since the 1950s, when chlorpromazine was introduced into psychiatric practice, antipsychotic drugs have been the cornerstone of the management of schizophrenia. They have three main functions: to treat the positive symptoms of acute schizophrenic episodes; to reduce schizophrenic relapse; and to manage the negative features of schizophrenia, although the evidence for their efficacy in this area is weaker. It is in relation to positive symptoms that the term treatment resistance is generally used. While the concept of treatment resistance remains ill defined, recent advances in drug treatment may bring better understanding of its underlying mechanisms.

It has been evident for many years that some cases of schizophrenia are resistant to treatment. In trials of conventional antipsychotic drugs about $30 \%$ of acute cases show only limited improvement ${ }^{1}$ and about $7 \%$ of these patients seem to show no response from the start of their illness. ${ }^{2}$ But the concept of treatment resistance remains ill defined. Kane $e t$ al used an operational definition-patients who failed to respond to two conventional antipsychotic drugs for six weeks ${ }^{3}$-while others have suggested a grading system ranging from total remission within one week on any treatment, to failure to respond after six months of drug and social treatment in hospital. ${ }^{4}$ Complete recovery with a sustained return to best premorbid functioning is not usual in patients with schizophrenia, and the point at which patients who do not materially improve can be described as resistant to treatment is therefore arbitrary. It is important to realise that not all patients who fail to respond are resistant to treatment; some may have received suboptimal treatment, perhaps because of poor compliance. However, limited response to treatment certainly occurs when drugs are being taken correctly, adequate plasma concentrations are achieved, and there is laboratory evidence of dopamine receptor blockade. ${ }^{5}$

\section{More than just $\mathrm{D}_{\mathbf{2}}$ dopamine receptor blockade}

The reality of treatment resistance in schizophrenia is emphasised by recent studies conducted on violent schizophrenic patients in special hospitals in England and Scotland. ${ }^{67}$ These patients are energetically treated with traditional and newer antipsychotic drugs in circumstances where compliance is as assured as it can ever be, and yet positive symptoms not only persist but are the basis in many cases of continuing disturbed and distressing behaviour. These patients are, of course, at the extreme end of the continuum of severity of schizophrenic illness, but our knowledge of why some should prove so resistant to therapeutic effort is sadly lacking.

In 1988 Kane et al caused an upsurge in interest in treatment resistance with their demonstration that schizophrenic patients who fulfilled an operational definition for treatment resistance showed definite group benefits when treated with clozapine as compared with standard treatment. ${ }^{3}$ Clozapine had been shown to be an effective antipsychotic drug in the 1970s, but its association with agranulocytosis (cumulative incidence of $0.8 \%$ after one year of exposure) ${ }^{8}$ delayed its widespread use. Its enhanced efficacy has been 